\title{
The challenges of alcohol addictions randomised control trials (RCTs): A nominal group technique (NGT) analysis
}

Eileen Brobbin ( $\nabla$ eileen.brobbin@kcl.ac.uk)

King's College London https://orcid.org/0000-0001-8464-4847

Jacklyn Dunne

King's College London

Laura Hermann

University of Hull

Andreas Kimergård

King's College London

Kim Donoghue

University College London

\section{Research Article}

Keywords: Nominal group technique, alcohol, addiction, RCT

Posted Date: May 12th, 2021

DOI: https://doi.org/10.21203/rs.3.rs-432672/v1

License: (9) This work is licensed under a Creative Commons Attribution 4.0 International License.

Read Full License 


\section{Abstract}

Background: Randomised controlled trials (RCTs) are considered the gold standard research design for assessing the efficacy of health care treatments and are essential for improving knowledge and outcomes. However, the challenges of running RCTs in the alcohol addiction field are rarely discussed. The Nominal Group Technique (NGT) is a method designed to encourage contributions and elicit agreement on what to prioritise. This paper aims to identify challenges of alcohol addiction RCTs and solutions to these challenges using the NGT.

Method: Six researchers from the Addictions Department, King's College London, experienced in running alcohol addiction trials as trial managers, principal investigators and chief investigators, took part in a two-round decision conference, which involved impartial facilitation, on-the-spot modelling and interactive group discussion according to the NGT. The data generated from the first session was viewed and refined in the second session to create a priority list of challenges and solutions for future alcohol addiction RCTs.

Results: The model produced a range of challenges when conducting alcohol addiction RCTs and solutions, which were rated according to priority by experts. After refinement of the model, these were categorised into five themes including: Staff, Recruitment, Follow ups, Governance and Funding. Each of these contained challenges and solutions when conducting alcohol addiction RCTs.

Conclusion: The challenges to running alcohol addiction RCTs were discussed by a group experienced in this area in order to promote discussion and solutions. The process of sharing experiences and ideas allows for furthering knowledge to improve the running of alcohol addiction RCTs. There were some challenges that were discussed where no solutions were known or thought of. Current research activity should be more open to discussing and sharing challenges and possible solutions to improve research outcomes.

\section{Background}

Alcohol misuse is one of the leading risk factors for ill health, early mortality and disability across all ages in England (1) and has been linked to more than 200 health conditions (2). In England, it was estimated that only 1 in 5 people in need of alcohol treatment are receiving it (3). With these challenges to public health, it is necessary and important to carry out high-standard alcohol research to improve prevention, intervention and treatment methods to reduce alcohol misuse.

Randomised controlled trials (RCT) are considered the gold standard research design for assessing the efficacy of healthcare treatments and are therefore essential for evidence-based healthcare and alcohol treatment (4). However, conducting high-quality RCTs can be challenging. Nearly a quarter of RCTs have been found to end prematurely (5), with an insufficient rate of participant recruitment being frequently cited as the cause of early study termination (5-7). Recruiting and retaining participants can be resource intensive and costly, as well as resulting in selection bias of participants $(8,9)$. Sully et al., (10) completed 
a review of trials funded by two UK funding agencies and found that $45 \%$ of trials did not recruit to their originally specified target and $45 \%$ of trials required an extension of the recruitment period to complete to target. A search of the ClinicalTrials.gov (October 2020) registry of clinical trials using the term "addiction, alcohol" returned 1122 registered RCTs. Looking further into those studies that have been terminated, withdrawn, or suspended; recruitment, funding, and staff were the top three reasons given (11). A further recognised challenge to conducting RCTs, is the often lengthy ethics and governance processes that can lead to delays in starting the trial, impacting on study timelines and funding budgets (12).

Alongside the challenges of conducting RCTs, conducting RCTs involving participants with alcohol and substance use disorders (AUDs and SUDs) pose further difficulties to recruitment and retention as certain characteristics of AUDs and SUDs may also decrease motivation to continue participation in research (13). This can be due to chaotic, unstable lifestyles and involvement in the criminal justice system (14). Alternatively, but also presenting challenges in participation, due to successful recovery and increased responsibility to work and family, participants may no longer want to engage in addiction related research (15). However, poor retention rates are not limited to these reasons.

Retention throughout follow-ups is important to reduce bias due to missing data $(14,16)$. It can also compromise a study's validity in two ways; firstly, due to follow-up rates being different between trial arms and, secondly, due to differences in participant characteristics amongst those dropping out. These two circumstances could affect the conclusions drawn from the study and not truly reflect the target populations (16). In previous trials, $70 \%$ has been used as the target follow-up rate however, it has been shown a follow-up rate of $70 \%$ may still lead to bias (14).

Another difficulty that must be considered when recruiting participants for alcohol addiction RCTs include where they are recruited from; as many are recruited from treatment services, those with AUDs and SUDs who are not in treatment may be underrepresented (17). It is a challenge to recruit participants with AUDs and SUDs not seeking or accessing treatment as they often have limited contact with healthcare services (18). Briel et al., also identified that reduced motivation of patients and recruiters as a cause for poor recruitment (6).

This study aimed to identify the challenges of conducting alcohol addiction RCTs, solutions to these challenges, and to generate a resource of options to improve the management and running of alcohol addiction RCTs.

There were three objectives: 1) To conduct a decision conference (19) (in two rounds) with trial managers, principal investigators and chief investigators of alcohol addiction RCTs; 2) To utilise the Nominal Group Technique (NGT) (19) to examine participants' perspectives on challenges and solutions while running alcohol addiction RCTs; and, 3) To generate consensus on the challenges of alcohol addiction RCTs, identify successful solutions to these while running addiction trials, and determine common options when conducting alcohol addiction RCTs. 


\section{Methods}

\section{Recruitment}

The study used the NGT (19) to analyse data collected in a two-round decision conference (20). Participants were recruited by volunteer sampling; researchers working in the Addictions Department, King's College London with experience as a trial manager, chief investigator, or principal investigator conducting RCTs in alcohol addictions were eligible to attend the two sessions.

\section{Group size}

Six staff members in the field of alcohol and addiction research participated in the group discussions. This group was small enough for all ideas and disagreements to be discussed and allowed for individual contribution and constructive problem solving (21).

\section{Structure of group discussions and data collection}

The two-day decision conference, held in 2018 , involved attendance by staff, impartial facilitation, on-thespot modelling and interactive group discussion (20). The NGT discussions contained non-verbal and verbal stages (19). During the first round (day 1), participants were asked to independently write down as many answers as possible to the following question: 'What challenges have you faced while running alcohol addictions trials?'After about 10 minutes, participants presented one answer at a time, while the facilitator wrote them down on computer connected to a large size monitor in the room for everyone to see. This continued until all answered were shared. The next stage within the first round consisted of structured discussions of all the answers, enquiring about support and non-support of each idea and identifying responses that were considered most important by the group. As such, the model was reviewed and refined by the participants. After a short break, the process started over again with a new question: 'What solutions have you used toward these challenges faced while running alcohol addictions trials?'Each solution from the participants was added to the screen and the model was then reviewed

and refined by them. The first round lasted for approximately 3.5 hours. During the second round (day 2), the refined model containing challenges and solutions was presented to the participants. A final model was developed on the monitor representing the consensus reached amongst the participants by identifying important categories. The second round lasted for approximately 1.5 hours.

\section{Data analysis}

The models containing challenges and solutions for conducting alcohol addiction RCTs that were created and refined during the two sessions, according to agreement and importance, were exported and saved as PDF files. Challenges and solutions that were identical but not removed during the interactive development of the model in the second decision conference round were removed during this stage of data analysis and data presentation. 
Firstly, all topics explored and included in the model after the first round of discussion are presented below (in table format) to include all points raised which may be appropriate when planning and running RCTs. Secondly, the refined model completed during the second conference round is presented below in table format followed by a narrative synthesis and presentation of the prioritised challenges and solutions.

\section{Results}

\section{Participants}

A total of six participants with experience in conducting RCTs in alcohol addiction participated, consisting of four females and two males. There was a combined 48 years of experience in addiction and alcohol research and a combined 39.5 years of experience working at the Addictions Department, King's College London. Combined, participants had completed 25 trials either as a trial manager, principal investigator or chief investigator. Of these, 22 were intervention trials and three were medication trials (Table 1).

Table 1. Participant demographics. 


\begin{tabular}{|c|c|}
\hline \multicolumn{2}{|l|}{ Participant characteristics } \\
\hline Gender & $N=6$ \\
\hline . $\quad$ Female $\mathrm{n}(\%)$ & $4(67 \%)$ \\
\hline Male n (\%) & $2(33 \%)$ \\
\hline \multicolumn{2}{|l|}{ Title } \\
\hline PhD student & $2(33 \%)$ \\
\hline Trial Manager & $1(17 \%)$ \\
\hline Research Fellow & $1(17 \%)$ \\
\hline Reader & $1(17 \%)$ \\
\hline Professor & $1(17 \%)$ \\
\hline \multicolumn{2}{|c|}{ Experience of alcohol addiction research (years) } \\
\hline Mean, median (SD) & $13,9.5(9.4)$ \\
\hline Range & $4-31$ \\
\hline \multicolumn{2}{|c|}{ Experience working at the Addictions Department (years) } \\
\hline Mean, median (SD) & $6.5,5(3.2)$ \\
\hline Range & $3.5-11$ \\
\hline \multicolumn{2}{|c|}{ Number of trials conducted (as trial manager, $\mathrm{PI}$ and $\mathrm{Cl}$ ) } \\
\hline Total & 25 (Range: 1-9) \\
\hline Intervention & 22 (Range: 1-8) \\
\hline Medication & 3 \\
\hline
\end{tabular}

Decision conference first round

For the question 'What challenges have you faced while running alcohol addiction trials?'the participants generated a total of 65 outcomes. After categorisation in the model, there were six themes under the following headings: Staff, Recruitment, Funding, Governance, Follow-ups, and Starting the Study. For the question 'What solutions have you used towards these challenges faced while running alcohol addiction trials?'the participants generated a total of 40 outcomes. After categorisation, there were four themes under the headings: Staff, Recruitment, Funding and Follow-ups. In the first round all challenges and all solutions were added to the model for discussion and refinement (Table 2).

Table 2. Model compiled during the first conference round. 


\begin{tabular}{|c|c|c|}
\hline Themes & $\begin{array}{l}\text { Challenges identified according to the } \\
\text { question posed ("What challenges have you } \\
\text { faced running alcohol addiction trials?") }\end{array}$ & $\begin{array}{l}\text { Solutions identified according to the } \\
\text { question posed ("What solutions } \\
\text { have you used towards these } \\
\text { challenges faced while running } \\
\text { alcohol addiction trials?") }\end{array}$ \\
\hline \multirow[t]{9}{*}{ Staff } & $\begin{array}{l}\text { High turnover of staff due to short-term } \\
\text { contracts }\end{array}$ & - Longer-term contracts \\
\hline & $\begin{array}{l}\text { Difficult to help progress academic } \\
\text { research career of short-term staff }\end{array}$ & $\begin{array}{l}\text { Ensure everyone is involved in } \\
\text { decision making }\end{array}$ \\
\hline & $\begin{array}{l}\text { An early career researcher working on a } \\
\text { long trial could mean few published papers } \\
\text { for CV which is important at this time in their } \\
\text { career }\end{array}$ & $\begin{array}{l}\quad \text { Give principle investigator a clear } \\
\text { role that is tangible and manageable } \\
\text { with respect to workload to increase } \\
\text { involvement }\end{array}$ \\
\hline & $\begin{array}{l}\quad \text { Applying for grants requires many } \\
\text { resources upfront and many centres are } \\
\text { unable to do this due to staff short-term } \\
\text { contracts }\end{array}$ & \\
\hline & $\begin{array}{l}\text { Researchers expected to write long } \\
\text { complex applications before receiving any } \\
\text { funding }\end{array}$ & \\
\hline & $\begin{array}{l}\quad \text { Bias to previously successful } \\
\text { researchers to receive funding, therefore } \\
\text { difficult for early career researchers to } \\
\text { progress }\end{array}$ & \\
\hline & $\begin{array}{l}\text { No dedicated central team for clinical } \\
\text { trial management unlike other areas of } \\
\text { research }\end{array}$ & \\
\hline & $\begin{array}{l}\text { Certain grants can lead to inflexibility } \\
\text { with staff recruitment }\end{array}$ & \\
\hline & $\begin{array}{l}\text { Market research versus academic } \\
\text { research (big difference in timelines and } \\
\text { thoroughness) }\end{array}$ & \\
\hline \multirow[t]{6}{*}{ Recruitment } & NHS recruitment & NHS recruitment \\
\hline & $\begin{array}{l}\text { NHS staff often have large caseloads, } \\
\text { therefore may prioritise caseloads over } \\
\text { research }\end{array}$ & $\begin{array}{l}\quad \text { Feasibility study assessing if it is } \\
\text { feasible for NHS staff to recruit and } \\
\text { provide interventions (but also delays } \\
\text { progress to completed trial) }\end{array}$ \\
\hline & $\begin{array}{l}\text { 1. NHS services often show low } \\
\text { commitment to recruitment }\end{array}$ & $\begin{array}{l}\text { Monetary incentives for NHS } \\
\text { practices }\end{array}$ \\
\hline & $\begin{array}{l}\text { Most NHS practices are not keen to take } \\
\text { part in research }\end{array}$ & \\
\hline & High turnover of NHS staff & \\
\hline & $\begin{array}{l}\text { Relying on individuals outside of the } \\
\text { research team likely to encounter some }\end{array}$ & \\
\hline
\end{tabular}




\section{School recruitment}

School staff often have large caseloads and other priorities

Safeguarding issues (example: schools wanted to use drinking data from students to help their students)

\section{Third sector charities recruitment}

High turnover of staff

\section{School recruitment}

Monetary incentives for schools

Third sector charities recruitment
High turnover of staff
New provider recruitment
. $\quad$ Potentially new policies to navigate
for researchers
foreates delays and is resource heavy
for researchers
. Relying on individuals outside of the
research team likely to encounter delays and
issues

\section{Non-service recruitment}

- Not recruiting through services (dependent on target population)

\section{Service recruitment and service staff}

- Incentives for key workers (example: theatre tickets, monthly engagement report, being more involved in how the trial is running)

- Incentivise research activity
- Make job descriptions of medical staff include taking part in clinical research

Make use of key workers (one client recruited may suggest to others)

Services exclusively focused on research/research intensive

- Assigning responsibility for recruitment to specific individuals for each site

\section{Other}

Researchers completing recruitment, baseline and follow-up is taxing and resource heavy

\section{Other}

- Word of mouth (when one student/patient says no to participating could influence others to say no and vice versa)

Care as usual (CAU) group (difficulty in services, providers, schools seeing the benefit of a CAU group in trial designs)

Adding research questions to small interventions can lead to lengthy assessments

Lengthy assessments can lead to difficulties in finding participants which meet
- $\quad$ Declined recruitment within group (best to try again another day)

Funding to employ workers for research specific jobs 
the study criteria and are willing to participate

Funding $\cdot$ Addictions and mental health are underfunded
Theme calls (more successful but may not be eligible for other schemes)

Combining with mental health still leads to unsuccessful funding (comorbidities are thought of differently to researchers with interventions currently being delivered for one psychopathology and no legitimate feedback for these applications)

- $\quad$ Limited knowledge of funders about addictions (comments back from funders show this gap, usually not anyone from a alcohol addiction speciality on a funding panel)

Many barriers in getting a trial started and running that could have immense evidence-based benefits to patients. However, money in the NHS can be used quite quickly to do something similar but without the rigorous process of research trials (implementation of intervention without efficacy research)

- Reduced turnover of patients through services

\section{Greater advocacy for mental health research}

- Joining panels that serve on grant committees (insights into how they think)
- Centre grants (would help keep expertise in teams and give people long term contracts (better for careers), brings teams together more and collaborate on practical problems; knowing who to contact, keeping things up to date and centralising resources) and networks with associated funding like UK Centre for Tobacco and Alcohol Studies (UKCTAS)
- Creating more collaborations

\begin{abstract}
- Evidence that patients who change providers may have poor outcomes providers may have poor outcomes
\end{abstract}


- Time from study idea to submitting proposal for funding is about 12 months (then additional time for any rejections. If funded, many more months to satisfy funding requirements)

Releasing the grant in small amounts at a time can create additional paperwork
- Service support costs (engaging to get service support costs before funding could help things progress more quickly - have conversations at the application stage, though it would add a lot of work in the pre-funding stage)

- $\quad$ No more small funding amounts as not enough to contribute to the study in a meaningful way (disproportionate effort in reporting to receive little money)

Lack of flexibility from funders (not understanding extensions and changing the design of the study and not sympathetic toward long process to make changes and delays)

Industry partners (managing their expectations, universities work very differently regarding contracts and reporting)
Being familiar with extension procedure, sometimes extensions are required to still meet all aims and easier to process than new grant applications

Funders can be inflexible (making it difficult to change the trial design during a grant when challenges arise)

- Negative study results (where to go, publishing, further funding, change in direction of research)

Governance - Clinical Research Network (CRN) moderate service support costs (can lead to many negotiations and delays)

If the service support costs are essential can delay study starting

Unclear responsibility (example: NHS commissioners of services are supposed to pay excess treatment costs but often they don't recognise this. For addiction services this is much harder as unclear who the commissioners are)

- Clinical Commissioning Groups (CCG) have policies but local authorities have no procedures in place and usually do not understand it is their responsibility, leading to delays

Difficult finding someone to speak to external organisations, even though many people contributing difficult to find the one responsible for the costs 
- These governance challenges are time consuming for researchers

- Demoralising to researcher staff when

they do not receive a response

$\begin{array}{ll}\text { Follow-ups } & \text { Low follow-up rates } \\ & \text { follow-up) }\end{array}$

Very resource heavy to obtain follow-ups and maintain a good rate throughout trial
- Training, policies and guidelines

- As a department, having an induction for researchers working with patients and policies in place

- Guidelines for researchers how to maximise recruitment, follow-ups in addiction trials (same as guidelines for clinicians)

- Balance between recruiting participants and completing follow-ups

- Improving tactics for obtaining data from participants

General Data Protection Regulation (GDPR) (sites afraid of releasing participant details)

All study sites responsible for all follow-ups, rather than only site specific follow-ups

Clarifying researcher role homes on their own)

- Assessments can be sensitive subject matters for researchers

Recruit Clinical Study Officers (CSOs)

Participants unclear of researcher's role

No specific duty of care after service discharge

Accountability for missing contact details process

- $\quad$ Limited training for researchers to support participants

Starting the study
Approval from governing parties takes an extensive time creates delays

- Leads to delays in recruitment and results in extensions which the research team is then blamed for as difficult to explain delays

- Supporting staff may not be completely familiar with the intricacies of the study design

- Difficulties in the manufacture and supply of placebo medication for clinical trials

Database validation (part time personnel working on the database which led to delays) 
Decision conference second round

In the second round, participants discussed the challenges and solutions identified in the first round and were able to evaluate, reorganise their decisions and prioritise the challenges and solutions. This resulted in a total of 16 prioritised challenges and 5 prioritised solutions (Table 3 ).

Table 3. Refined model during the second conference round: Prioritised challenges and solutions. 


\begin{tabular}{|c|c|c|}
\hline Themes & Challenges & Solutions \\
\hline \multirow[t]{3}{*}{ Staff } & Contract lengths & \\
\hline & $\begin{array}{l}\text { - Limited pool of applicants with the right } \\
\text { qualifications }\end{array}$ & \\
\hline & Writing new grants with limited resources & \\
\hline \multirow[t]{4}{*}{ Recruitment } & Rely on services to refer but many & - Incentivise services \\
\hline & $\begin{array}{l}\text { services/ service providers are non-researcn } \\
\text { minded' }\end{array}$ & - More input from clinical staff \\
\hline & $\begin{array}{l}\text { Services change due to commissioning } \\
\text { and staff changes }\end{array}$ & \\
\hline & $\begin{array}{l}\text { Clinicians not taking sufficient contact } \\
\text { details and consent }\end{array}$ & \\
\hline \multirow[t]{5}{*}{ Follow-ups } & $\begin{array}{l}\text { Participants can be vulnerable, young and } \\
\text { intoxicated }\end{array}$ & $\begin{array}{l}\text { Reduce the length of the follow-up } \\
\text { assessment, prioritising the collection } \\
\text { of primary outcome data }\end{array}$ \\
\hline & $\begin{array}{l}\text { Assessments demand too much from } \\
\text { participants }\end{array}$ & $\begin{array}{l}\text { - Managing expectations of the } \\
\text { participant }\end{array}$ \\
\hline & $\begin{array}{l}\text { Alcohol withdrawal sets in and limits the } \\
\text { time to complete an assessment }\end{array}$ & \\
\hline & $\begin{array}{l}\text { Participants treating researchers as case } \\
\text { workers }\end{array}$ & \\
\hline & $\begin{array}{l}\text { Disappointment in being randomised to } \\
\text { the care as usual (CAU) arm of the trial }\end{array}$ & \\
\hline Governance & $\begin{array}{l}\text { Length of time it takes to complete the } \\
\text { procedures and lots of organisations to } \\
\text { deal with external to the college }\end{array}$ & \\
\hline \multirow[t]{4}{*}{ Funding } & $\begin{array}{l}\text { Alcohol addiction is a small field resulting } \\
\text { in non-specialists reviewing proposals }\end{array}$ & - Permanent contracts \\
\hline & Non-flexible funding & \\
\hline & Length of time to secure funding & \\
\hline & Lack of continuity in the research team & \\
\hline
\end{tabular}

Decision conference second round: Narrative presentation

Staff

There were three challenges prioritised for staffing; high staff turnover due to short contract lengths, limited pool of applicants with the right qualifications in addictions, especially due to the restrictions for funding (funding for grade 5/Research Assistant only), and the difficulty of writing new grants with 
limited funding, resources, number of staff in post and staff time. There were no solutions prioritised for this.

\section{Recruitment}

The model identified the following as important challenges; alcohol addiction services as 'non-researchminded' and services change over the course of RCTs due to commissioningstaff turnover as important challenges. Moreover, clinicians not taking verbal consent or sufficient details to enable the researcher to contact potential referred participants were found to lead to difficulties in recruiting for RCTs.

As part of the study designs, alcohol addiction researchers often relied on service providers to refer participants, however, difference in mind-set towards the importance and priority of research could lead to challenges. The changes within services can also negatively impact recruitment, for example, if treatments necessary for eligibility are not carried out for a period of time due to financial constraints (such as alcohol detoxifications being cancelled during recruitment to a RCTs which requires participants to have completed detoxification). Furthermore, when clinicians aid recruitment by informing patients and collecting contact details for referrals, the model found that often the clinician had not sufficiently or clearly enough informed the participant of the research and their role/expectations when taking part. Obtaining limited details that would make it difficult for the researcher to contact the referral emerged in the model as an important challenge in alcohol addiction RCTs.

Solutions that were prioritised in the model include, incentivised recruitment at addictions services and to collect more input from clinical alcohol service staff at the grant writing stage.

\section{Follow-ups}

The vulnerability and difficulty in working with this population of people, who are alcohol dependent or suffer from AUDs, lengthy assessments, expecting too much from the participants, participants in alcohol withdrawal, and participants treating researchers as their caseworker resulting in confusion in the relationship, were further challenges identified in alcohol addiction RCTs. Disappointment from participants when randomised to care as usual (CAU) presented challenges which were hard to overcome. In the alcohol addiction treatment field, CAU often means no treatment at all due to cuts in services and difficulties navigating treatment paths.

In alcohol addiction RCTs, participants can be vulnerable, young, and intoxicated. Researchers need to receive training in working with this group to utilise their research skills and collect information from the participant, sometimes in unconventional circumstances. Assessments can often be lengthy, expecting a lot of information from the participant, be of a sensitive nature and withdrawal could set in and limit the time to complete the assessment.

Solutions that were prioritised included reducing the length of assessments by prioritising primary outcome data and managing expectations when informing and recruiting participants. 


\section{Governance}

There was one challenge that was prioritised for governance that was the length of time procedures take.

The length of time it takes to complete the governance procedures that many organisations request in alcohol addiction research relies on services and organisations external to the university (funders, ethics committees and R\&D departments). The duration of this process is often underestimated and cannot be covered by funding from research grants (or typically underfunded according to the model).

There were no solutions prioritised for this.

\section{Funding}

Four challenges were prioritised for funding: non-addiction specialists reviewing proposals, non-flexible funding, length of time to secure funding and lack of staff continuity.

Addictions is a relatively small research field which often results in non-specialists reviewing proposals for alcohol addiction RCTs, which in turn may lead to rejections as the topic may not be considered a current priority for funding. In addition it may be misunderstood and/or receive poor feedback preventing the project moving forward. Non-flexible funding also means that research must follow exactly what was stated in the proposal, although often, as time has passed updated knowledge is available and circumstances can change priorities. The length of time to secure funding and the lack of continuity in the research team over this period of time, due to staff being on short-term contracts, also lead to funding challenges.

A prioritised solution for this was increased use of permanent staff contracts.

\section{Discussion}

During a decision conference using NGT (19), this study aimed to identify and generate a consensus model of important challenges and to identify successful solutions in order to contribute to the effective running of alcohol addiction RCTs. The study found that the challenges and solutions put forward and refined in the model during two rounds of decision conferences could be organised into five overarching themes; Staff, Recruitment, Follow ups, Governance, and Funding. The findings of this study offer firsthand experience and support previous findings that identify the main reasons for trials ending prematurely. As such, recruitment, funding, and staff were the top three reasons given on ClinicalTrials.gov for alcohol addiction trials being terminated or withdrawn (11), with uncompleted trials representing wasted time and resources.

Each theme had solutions that varied in resources, effort, and time required. Some solutions were simple, less resource intensive and involved changes to how tasks are completed by the researcher. Other solutions suggested changes in how alcohol services run on a much larger scale, which would require support from other institutions and additional funding. For example, although a current challenge is that 
addictions and mental health research are underfunded, there has been an improvement in recent years (22) and this could improve further in the future, depending on macro-level structural changes and funding.

Many of the challenges across all themes in the model related to increasing delays in running alcohol addiction RCTs, which were time-consuming and resource heavy for researchers. Delays and timeconsuming tasks all equate to researchers having less time available to spend on research activity, which impacts on financial costs and research outcomes (12). Sully et al., (10) investigated the state of recruitment and found that both time extensions and additional financial requirements were often requested; the researchers promoted the need for strategies to mitigate this. Delays can negatively affect the impact of the research, for example by the research being outpaced, failing to answer the research question in time with the most up to date knowledge and technology (23), in addition to the workload when requiring extensions of grants and contracts.

Challenges that were also elicited included the time required by the participant to complete often lengthy assessments and also the time and resources required by researchers for sufficient recruitment and follow up completion. Another challenge linked to recruitment was the varying levels of motivation from recruiters (researchers as well as external collaborators such as in alcohol services). A recent study by Briel et al., (2019) compared RCTs discontinued or revised for poor recruitment to completed RCTs with the similar research question. Their results found various reasons for poor recruitment, including, higher burden for patients/participants and recruiters and reduced motivation of patients/participants and recruiters (6). This suggests that focusing on reducing the burden for both patients and recruiters and ensuring a sustained motivation would be beneficial for trial completion, reducing the impact of challenges of recruitment and retention on the trial $(14,16)$. In this study, the model found that a suggested solution included the use of incentives, however this solution will not be suitable for all RCTs as incentivising recruitment with service staff will typically depend on funding.

At the time of writing up the results, we have experienced a change in how research is completed as a rapid response to the COVID-19 global pandemic; seeing accelerated governance and ethics approvals for clinical studies, rapid set up of research and implementation of study findings. This has been the result of a collaborative approach across many institutions, health authorities and organisations. The National Institute for Health Research (NIHR) and in the UK and UK Research and Innovation (UKRI) reaction, prioritisation and speed of delivering funding have led to clinical trials with expedient outcomes (24-27). It has been imperative to produce research results, but it also suggests that quicker approvals processes, trial set up, and delivery is possible to achieve, although possibly with greater costs and when research has a certain focus (such as the COVID-19 pandemic). The experience of rapid approval and implementation of research could be used going forward to aid all research efforts and negotiate some of the challenges in conducting RCTs identified in this study. This will not only benefit researchers and companies but also patient outcomes (24). 
Although most, if not all, of those conducting RCTs will likely be aware of the potential challenges, there is not a large body of research to refer to when trying to resolve these problems. There is limited research reflecting the challenges of running alcohol addiction trials in particular, however, the points elicited here, and agreement of these in the decision conferences, suggest that every researcher who took part in this study had experienced them within trials they had been involved in, and in most cases there were also solutions that a researcher had found which could be implemented. Challenges and solutions and consensus of experts in the field of alcohol addiction have not previously been explored using this technique (NGT).

RCTs are important in assessment and innovations in the alcohol addiction field but their challenges need to be addressed, minimised, and solved to make full use of their advantages. Working in the alcohol addiction field comes with its own challenges, but with collaboration between researchers, solutions can be shared, discussed, and implemented to conduct effective and efficient RCTs with less difficulty, as suggested by some of the solutions presented in this study. However, it was also found that for some challenges there were no clear solutions, after prioritising challenges there were certain themes with no solutions, this could be an interesting area for future research.

\section{Limitations}

Although the invitation for the sessions was sent to every researcher in the Addictions Department, King's College London of whom had experience as a trial managers, chief investigators or principal investigators leading RCTs in addictions, only six attended and all happened to be in the alcohol addiction field. This was advantageous in allowing participants to discuss specifically within this area but is also therefore limited the scope of the model to alcohol. Further research would be required to assess the generalisability of findings produced in the model across other SUDs and RCTs in general.

Within the two sessions, there was a facilitator who wrote the suggestions down on a large size monitor in the room for everyone to see. However, it can be hard to summarise hours of discussion into succinct points and ultimately there will be some details lost. Furthermore, the sessions were audio recorded as a precaution, however no time points were made so to listen back and the audio files were not transcribed for analytical purposes. However, in both of these cases, this is not the intention of the NGT. Rather, it is to arrive at a model containing overarching challenges and solutions that was achieved.

\section{Conclusion}

This study indicates the importance of exploring and identifying solutions to the challenges encountered while conducting alcohol addiction RCTs. However, we suggest an overlap between findings in the model concerning alcohol addiction RCTs and challenges encountered in other substance use and addiction trials, as well as in RCTs in other research fields. Research is important in improving patient outcomes, better health system performance and improving knowledge, but the challenges of running RCTs need to be minimised for optimum impact. This paper adds to the limited literature on the challenges of running alcohol addition trials whilst adding solutions that have been used and thought of by experienced 
researchers in the alcohol field. In the future, researchers should consider these potential challenges and solutions when designing and conducting their own trials in order to minimise challenges that may occur.

\section{Abbreviations}

\begin{tabular}{ll} 
Abbreviation & Explanation \\
\hline$A U D$ & Alcohol Use Disorder \\
$C A U$ & Care as Usual \\
\hline$C C G$ & Clinical Commissioning Group \\
\hline$C R N$ & Clinical Research Network \\
\hline $\boldsymbol{C S O}$ & Case Study Officer \\
\hline GDPR & General Data Protection Regulation \\
\hline NIHR & National Institute for Health Research \\
\hline NGT & Nominal Group Technique \\
\hline $\boldsymbol{R C T}$ & Randomised Controlled Trial \\
\hline $\boldsymbol{R} \& D$ & Research and Development \\
\hline SUD & Substance Use Disorder \\
\hline UKCTAS & UK Centre for Tobacco and Alcohol Studies \\
\hline UKRI & UK Research and Innovation
\end{tabular}

\section{Declarations}

Ethics approval and consent to participate

Participants were expressing their viewpoints within their professional competence and the subject limited to the standard of practice of conducting alcohol addiction RCTs in the Addictions Department at King's College London. The data is anonymous and not considered to be sensitive or confidential in nature. Participation was voluntary. Ethical approval was not required.

Consent for publication

Not applicable.

Availability of data and materials

Not applicable. 
Competing interests

Andreas Kimergård was appointed to the list of experts for 2020-2023 used by the EU drug agency, the EMCDDA, for the assessment of risks posed by NPS. No other conflicts of interest to declare.

\section{Funding}

The authors received no specific funding for this work. AK, King's College London, is supported by the National Institute for Health Research (NIHR) Applied Research Collaboration South London (NIHR ARC South London) at King's College Hospital NHS Foundation Trust. The views expressed are those of the author and not necessarily those of the NIHR or the Department of Health and Social Care.

\section{Authors' contributions}

$\mathrm{KD}$ and $\mathrm{AK}$ conceived and designed the work. $\mathrm{KD}$ and JD facilitated the conference decisions round and completed the model on the screen. EB analysed the model and led on writing the manuscript. All authors commented, edited and reviewed the manuscript. All authors read and approved the final manuscript.

\section{Acknowledgements}

We would like to acknowledge those that participated in the group discussions.

\section{References}

1. Forouzanfar MH, Afshin A, Alexander LT, Biryukov S, Brauer M, Cercy K, et al. Global, regional, and national comparative risk assessment of 79 behavioural, environmental and occupational, and metabolic risks or clusters of risks, 1990-2015: a systematic analysis for the Global Burden of Disease Study 2015. Lancet. 2016;388(10053):1659-724.

2. World Health Organisation. Global status report on alcohol and health 2014. 2014;1-392. Available from: http://www.who.int/substance_abuse/publications/global_alcohol_report/msbgsruprofiles.pdf

3. PHE. Alcohol and drug treatment for adults: statistics summary 2017 to 2018 . Natl Stat [Internet]. 2018;19. Available from: https://www.gov.uk/government/publications/substance-misuse-treatmentfor-adults-statistics-2017-to-2018/alcohol-and-drug-treatment-for-adults-statistics-summary-2017-to2018\#age-groups

4. Bothwell LE, Greene JA, Podolsky SH, Jones DS. Assessing the Gold Standard - Lessons from the History of RCTs. N Engl J Med. 2016;374(22):2175-81.

5. Kasenda B, Von Elm E, You J, Blümle A, Tomonaga Y, Saccilotto R, et al. Prevalence, characteristics, and publication of discontinued randomized trials. JAMA - J Am Med Assoc. 2014;311(10):1045-51.

6. Briel M, Speich B, Von Elm E, Gloy V. Comparison of randomized controlled trials discontinued or revised for poor recruitment and completed trials with the same research question: A matched qualitative study. Trials. 2019;20(1). 
7. Cullati S, Courvoisier DS, Gayet-Ageron A, Haller G, Irion O, Agoritsas T, et al. Patient enrollment and logistical problems top the list of difficulties in clinical research: A cross-sectional survey. BMC Med Res Methodol. 2016;16(1):1-9.

8. Patel MX, Doku V, Tennakoon L. Challenges in recruitment of research participants. Adv Psychiatr Treat. 2003;9:229-38.

9. Myers BA, Pillay Y, Guyton Hornsby W, Shubrook J, Saha C, Mather KJ, et al. Recruitment effort and costs from a multi-center randomized controlled trial for treating depression in type 2 diabetes. Trials. 2019;20(1):1-10.

10. Sully BGO, Julious SA, Nicholl J. A reinvestigation of recruitment to randomised, controlled, multicenter trials: A review of trials funded by two UK funding agencies. Trials. 2013;14(1):1-9.

11. Clinicaltrials.gov. No Title [Internet]. 2020 [cited 2020 Oct 25]. Available from: https://clinicaltrials.gov/

12. Bentley C, Cressman S, van der Hoek K, Arts K, Dancey J, Peacock S. Conducting clinical trials-costs, impacts, and the value of clinical trials networks: A scoping review. Clin Trials. 2019;16(2):183-93.

13. DiClemente CC, Schlundt D, Gemmell L. Readiness and Stages of Change in Addiction Treatment. Am J Addict. 2004;13(2):103-19.

14. Scott CK. A replicable model for achieving over $90 \%$ follow-up rates in longitudinal studies of substance abusers. 2004;74(1):21-36.

15. Tompkins CNE, Neale J, Marsden J, Strang J. Factors influencing recruitment to a randomised placebo-controlled trial of oral naltrexone and extended release implant naltrexone: Qualitative study. J Subst Abuse Treat. 2019;99:52-60.

16. Dettori JR. Loss to Follow-Up. Evid Based Spine Care J. 2011;103(3):1037.

17. Uhlmann S, Milloy MJ, Ahamad K, Nguyen P, Kerr T, Wood E, et al. Factors associated with willingness to participate in a pharmacologic addiction treatment clinical trial among people who use drugs. 2015;24(4):2020.

18. Korte J, Wakim P, Rosa C, Perl H. Addiction treatment trials: how gender, race/ethnicity, and age relate to ongoing participation and retention in clinical trials. Subst Abuse Rehabil. 2011;205.

19. Scott D, Deadrick D. The nominal group technique: Applications for training needs assessment. 1982;

20. Phillips LD, Bana E Costa CA. Transparent prioritisation, budgeting and resource allocation with multi-criteria decision analysis and decision conferencing. Ann Oper Res. 2007;154(1):51-68.

21. Phillips LD. Group dynamics processes for improved decision making. 2010. 2128-2135 p.

22. NHS. NHS strengthens mental health support for staff [Internet]. 20.10.2020. [cited 2020 Dec 3]. Available from: https://www.england.nhs.uk/2020/10/strengthening-mental-health-support-for-staff/

23. Rosas SR, Schouten JT, Dixon D, Varghese S, Cope MT, Marci J, et al. Evaluating protocol lifecycle time intervals in HIV/AIDS clinical trials. Clin Trials. 2014;11(5):553-9.

24. Hallsworth M. Rapid change COVID-19 \& UK clinical research Follow us. Pharmafield. 2020; 
25. Mahase E. Covid-19: Hydroxychloroquine does not benefit hospitalised patients, UK trial finds. BMJ. 2020;369(June).

26. Mahase E. Covid-19: Oxford vaccine is up to $90 \%$ effective, interim analysis indicates. BMJ. 2020;371.

27. HRA. Fast track review guidance for COVID-19 studies - Health Research Authority [Internet]. 2020 [cited 2020 Dec 7]. p. 19. Available from: https://www.hra.nhs.uk/covid-19-research/fast-trackreview-guidance-covid-19-studies/ 